\title{
CLINICAL OUTCOMES OF TWO-STAGE DELAYED COLO-ANAL ANASTOMOSIS: A LITERATURE REVIEW
}

\author{
Anass Mohammed Majbar, Amine Benkabbou, Laila Amrani, Raouf Mohsine, Amine Souadka.
}

Digestive surgical oncology department, National Institute of Oncology, Rabat, Morocco. Medical school of Rabat, Mohammed $\mathrm{V}^{\text {th }}$ University of Rabat, Rabat, Morocco.

\begin{abstract}
Delayed anastomosis after rectal surgery was first described by Turnbull and Cutait for Hirschprung's disease, Chagas disease, and rectal cancer. The main objective of this technique is to reduce the risk of anastomotic fistula (AL), thanks to the adhesions that are created between the lowered colon and the anal canal between the first and second operative stages. This technique has seen a revival of interest in recent years, visible in the high number of publications in the last decade. Actual indications for delayed colo-anal anastomosis (DCA) are low rectal cancer and challenging situations in rectal surgery, mainly failed colorectal or colo- anal anastomosis. The rate of pelvic septic complications (anastomotic fistula and pelvic abscess) varies between 0 and $35.3 \%$, with most studies reporting low rates. The rate of salvage ostomy creation in the postoperative period varied from 0 to $18.7 \%$. Mortality was NUL in the majority of studies. The rate of poor functional results varied from 0 to $38.5 \%$ and functional outcomes appear to improve over time. Few studies compared DCA to one-stage colo-anal anastomosis, with contradictory resulats. These results should be taken with caution because of the low level of available evidence. The ongoing randomized trials, comparing DCA with one-stage colo-anal anastomosis, will define the place of DCA in rectal surgery.
\end{abstract}

Keywords: Rectal neoplasms, Delayed colo-anal anastomosis, Anastomotic fistula

Corresponding Author:

Anass Mohammed Majbar, MD.

Address: Digestive surgical oncology department. National Institute of Oncology. Rabat, Morocco

E-mail: anass.majbar@um5s.net.ma

Copyright (C) 2012- 2021 Anass Mohammed Majbar et al. This is an open access article published under Creative Commons Attribution -Non Commercial- No Derives 4.0 International Public License (CC BY-NC-ND). This license allows others to download the articles and share them with others as long as they credit you, but they can't change them in any way or use them commercially.

****** Published in 2021

doi: $10.46327 / \mathrm{msrjg} .1 .000000000000----$

doi url: https://doi.org/10.46327/msrjg------

\section{INTRODUCTION}

Delayed anastomosis after rectal surgery was first described by Turnbull and Cutait for Hirschprung's disease, Chagas disease, and cancer of the upper rectum and sigmoid [1,2]. It was then described in surgery for cancer of the lower rectum [3] and lately as a rescue technique in difficult colorectal surgery situations [4]. The principle of this technique is to perform the colo-anal anastomosis in two operative stages. The first stage, after rectal resection, 5 to $10 \mathrm{~cm}$ of the colon is externalized transanally and is kept outside. The second stage, which is carried out a few days later, the exteriorized colon is sectioned, then the anastomosis is fashioned [5,6].

The main objective of this technique is to reduce the risk of anastomotic fistula (AL), thanks to the adhesions that are created between the lowered colon and the anal canal between the first and second operative stages $[1,2]$. The other advantage is to avoid the use of a protective ileostomy, given the low theoretical risk of occurrence of anastomotic fistula $[6$, 
7]. The initial reported results were promising with respect to the reduction of pelvic septic complications, but the functional results were mixed $[6,8]$.

This technique was popular during the 70 s and 80 s of the last century, then was gradually abandoned, probably by the widespread use of mechanical circular staplers and colonic pouch construction techniques, which greatly improved the functional results after rectal surgery [9]. Nevertheless, the rate of anastomotic fistulas in coloanal anastomosis remains high, and is associated with significant morbidity and mortality and poor long-term functional and oncological results [10-12].

As a result, this technique has seen a revival of interest in recent years, visible in the high number of publications in the last decade $[13,14]$. The objective of this article is to make a review of the literature synthesizing the main recent results of this technique, essentially morbidity, mortality and functional results.

\section{INDICATIONS}

The principle of delayed anastomosis was first described separately by Cutait and Turnbull for the surgical treatment of Hirschprung's disease, Chagas disease and cancer of the upper rectum and sigmoid [1, 2]. In the technique described by Cutait [1], the rectum was eversed transanally, and the colon was exteriorized through the rectum. A delayed colorectal anastomosis was performed 7-10 days later.

For rectal cancer, with the increasing adoption of sphincter preservation, the indications of this technique have widened to cancers of the middle then of the lower rectum, with lower colorectal anastomosis $[6,7,15]$. Currently, the majority of authors reserve this technique for cancers of the lower rectum, with the creation a delayed colo-anal anastomosis [5, 13, 16, 17].

Recently, the indications for delayed colo-anal anastomosis (DCA) were extended to more challenging colorectal surgery cases, mainly the complications of failed colorectal or colo-anal anastomosis. DCA was applied in case of chronic pelvic sepsis, recto-vaginal fistula (RVF), colovesical fistula, colonic ischemia, and recto-urinary fistula [4, 17-19]. Finally, DCA was also used for complicated Crohn disease, complex perianal fistula, diverticulitis and pelvic injury [9].

\section{SURGICAL TECHNIQUE}

We will mainly report the technique as described by Baulieux [3, 20] for cancer of the lower rectum. The variations of the technique proposed by other authors will be specified in the text if necessary.

The surgery is done in two stages. During the first operative stage, rectal or colonic resection is performed and the colon is externalized by the transanal route. During the second operating stage, the excess colon is cut and the anastomosis is made.

\section{FIRST STAGE}

The intervention begins with the abdominal approach. Two important elements have to be performed: sufficient colonic mobilization allowing a tensionless lowering of the colon towards the perineum, and a pelvic dissection up to the levator- ani plane to facilitate the perineal approach.

If it is rectal cancer, surgery can be done by laparoscopy or laparotomy. In both cases, the patient is installed in the modified Lloyd-Davis position. The mesenteric artery is controlled at its origin and the mesenteric vein is controlled at the lower edge of the pancreas, to facilitate the lowering of the colon towards the perineum. The splenic angle is detached and the left half of the transverse colon is mobilized. Then, the rectum is dissected circumferentially, in the plane of the fascia recti, to the level of the levator-ani muscles. In case of iterative surgery for complication of rectal surgery (rectovaginal fistula; perineal sepsis ...), the intervention is more challenging and it is often necessary to mobilize the transverse colon or the right colon more widely to allow a sufficient lowering of the colon to the perineum. To this end, specific lowering maneuvers may be necessary, such as the transmesenteric or Deloyers maneuvers [4, 21].

Then, the surgeon proceeds to the perineal approach. The exposure is facilitated by a Lone-Star type retractor or equivalent. The injection of saline serum with adrenaline under the mucosa is advised to facilitate mucosectomy. An incision of the rectal mucosa is made with cautery, above the pectineal line. The rectum is closed with sutures and the dissection continues to join the abdominal dissection plane. Once the rectum is completely released, the surgical specimen is externalized transanally. If the rectum is too large compared to the pelvis, the extraction through the abdominal incision to avoid an opening of 
the intestine. After the colonic section, 5 to $10 \mathrm{~cm}$ of the colon is left outside. Sutures between the anal canal and the colonic seromuscular are made to avoid colonic retraction and are left long, as guides to facilitate the second operating stage. The exteriorized colon is sutured on the inner side of the thigh to avoid any discomfort to the patient during the waiting period [22]. A pelvic suction drain, externalized by the abdomen is reported by most authors. The colon is protected by a dressing soaked in paraffin and it is inspected daily to check its viability.

\section{SECOND STAGE}

It can be performed between the fifth and the fourteenth postoperative day $[17,20,23]$. The patient is installed in the modified Lloyd-Davis position, under spinal-anesthesia or general anesthesia. Several variants have been described. Baulieux et al. [20] performs the anastomosis at the level of the pectineal line. Kirwan and then Bianco proposed to perform the anastomosis higher than the pectineal line. For this, the adhesions between the lowered colon and the anal canal are released a high colo-anal anastomosis is made by interrupted sutures [6,23]. Other authors have insisted on respecting the adhesions which have been created between the colon and the anal canal. They propose a colonic section at the level of the anal margin, and the colo-anal anastomosis is made by resorbable interrupted sutures.

\section{MORBIDITY-MORTALITY}

The main theoretical advantage of delayed anastomosis is to reduce the rate of anastomotic fistulas (AF) after rectal resection [1]. Initial results for delayed colorectal anastomosis showed a lower rate of $\mathrm{AF}$ for delayed anastomosis compared to one-stage anastomosis $[1,8]$.

For delayed coloanal anastomosis, some studies have reported the rates of $\mathrm{AF}$ and pelvic abscess (without AF) separately while others have reported them together. For the sake of consistency, we will report the overall rate of pelvic septic complications, including AF and pelvic abscesses. Table I summarizes the morbidity results in the literature. The rate of pelvic septic complications varies between 0 and $35.3 \%$ (Table 1). It should be noted that three out of 14 studies reported no pelvic septic complications $[16,19,24]$. Few studies compared the rate of septic complications between DCA and one-stage coloanal anastomosis with contradictory results. Zanguie et al. reported a lower rate for DCA (12.3\% vs. 24.9\%)[25]. In contrast, Prete et al. reported a higher rate in the DCA group (18.7\% vs. 0) [26] 
Table I: Characteristics of studies and morbidity results

\begin{tabular}{|c|c|c|c|c|c|c|}
\hline Author & $\mathbf{n}$ & Diagnosis & Salvage Ostomy & Pelvic sepsis & Reoperation & Death \\
\hline Zanguie 2018 & 49 & Cancer & NP & $6(12.3 \%)$ & NP & NP \\
\hline Jarry 2011 & 100 & Cancer & 7 & $10(10 \%)$ & $14(14 \%)$ & $3(3 \%$ \\
\hline Facy 2009 & 17 & Cancer & $2(11.8 \%)$ & $2(11.8 \%)$ & $3(17.6 \%)$ & $1(5.8 \%)$ \\
\hline Baulieux 2004 & 46 & Cancer & $1(2.2 \%)$ & $2(4.3 \%)$ & $1(2.2 \%)$ & 0 \\
\hline Sage 2018 & 85 & Cancer & NA & $30(36.3 \%)$ & $9(10.6 \%)$ & $2(2.3 \%)$ \\
\hline Barugola 2018 & 9 & Cancer & NA & $2(22.2 \%)$ & 0 & 0 \\
\hline Xiong 2016 & 72 & Cancer & 0 & $2(2.8 \%)$ & 0 & 0 \\
\hline Bianco 2016 & 8 & Cancer & 0 & 0 & 0 & 0 \\
\hline Maggiori 2015 & 24 & Failed anastomosis & NA & $3(12.5 \%)$ & $4(16.7 \%)$ & 0 \\
\hline Hallet 2014 & 7 & Failed anastomosis & $1(14.3 \%)$ & $1(14.3 \%)$ & $1(14.3 \%)$ & 0 \\
\hline Pujahari 2014 & 8 & Cancer & 0 & 0 & 0 & $1(12.5 \%)$ \\
\hline Prete 2013 & 16 & Cancer & $3(18.7 \%)$ & $3(18.7 \%)$ & $3(18.7 \%)$ & 0 \\
\hline Fixot 2013 & 2 & Recto-urinary fistula & NA & 0 & 0 & 0 \\
\hline Biondo 2012 & 13 & Cancer / Failed anastomosis & $1(7.7 \%)$ & $2(15.4 \%)$ & $5(38.5 \%)$ & 0 \\
\hline Kirwan 1978 & 84 & Cancer & 0 & $6(7.1 \%)$ & $1(1.2 \%)$ & 0 \\
\hline Remzi 2009 & 76 & Cancer / Complicated cases & NP & $2(3 \%)$ & NP & 0 \\
\hline
\end{tabular}

NA: Not applicable / NP: Non reported

The rate of reinterventions varies between 0 and $38.5 \%$ [4-6, 9, 17-19, 24, 25, 27-31]. The main causes are pelvic septic complications and necrosis of the lowered colon. These complications often required the creation of a salvage ostomy which can be temporary or permanent. In patients who did not have an ostomy, the rate of salvage ostomy creation in the postoperative period varied from 0 to $18.7 \%$ $[13,14,16,26]$.
Mortality was NUL in the majority of studies. Only one Indian study reported a rate of $12.5 \%$, corresponding to a death in a series of 12 patients [24]. In the long term, the rate of permanent ostomies varied from 0 to $25 \%$. The main definitive stoma causes were pelvic septic complications and anal incontinence. The rate of definitive ostomy was higher in series including complex situations $[4,9,18]$. Remzy et al. who reported the highest failure rate of $25 \%$ from DCA included in $58 \%$ complex situations [9], while Maggiori et al. who reported a final ostomy rate of $21 \%$, included only patients with failed colorectal or colo-anal anastomosis [4]. 


\section{FUNCTIONAL RESULTS}

The functional results are difficult to assess because the evaluation methods were different in the literature with contradictory results. Table II presents the results of the main studies in the literature. The rate of poor functional results varied from 0 to $38.5 \%$

Table II: Functional results in the litterature

\begin{tabular}{llll}
\hline Author & Mean follow-up & Evaluation method & Poor functional results \\
\hline Kirwan 1979 & At least 12 months & Custum questionnaire & $15 / 29(38.5 \%)^{*}$ \\
Jarry 2011 & At least 24 months & Wexner score & $25 / 94(27 \%)^{*}$ \\
Facy 2009 & 35.3 months & Wexner score & $0 / 16^{*}$ \\
Maggiori 2015 & 29 months & LARS score & $3 / 17(18 \%)$ \\
Zanguie 2019 & At least 12 months & Wexner score & $17 / 59(29 \%)^{*}$ \\
\hline
\end{tabular}

* Wexner score > 10 / LARS: Low Anterior Resection Syndrome

Zanguie et al. reported a median 1-year Wexner score of 6.4 , with $29 \%$ of patients having poor results (score $>10)[25]$. In the largest series in the litterature (100 patients with low rectal cancer), the rate of poor functional outcomes according to Wexner score was $27 \%$ [27]. Maggiori et al. who included only failed colorectal or colo-anale anastomosis cases, reported an $18 \%$ rate of poor functional outcomes [4].

Functional outcomes appear to improve over time. Olagne et al. showed that poor functional outcomes (Wexner score $>10$ ) decreased from $73 \%$ at one month to $0 \%$ at 60 months [3]. Similarly, Jarry et al. showed a decrease of poor functional outcomes, from $55 \%$ in the first year, to $27 \%$ after 24 months [27].

Remzi et al. compared the functional results between ACAD and direct coloanal anastomosis. The Wexner score was not statistically different between the two techniques (10.6 vs. $12.2 . \mathrm{P}=0.09)$. There was also no difference for each question of the Wexner score [9].

\section{CONCLUSION}

Delayed colo-anal anastomosis is a feasible technique with acceptable morbidity and mortality. In particular, the pelvic septic complications seem to be lower compared to the one-stage colo-anal anastomosis. The functional results are acceptable, with a significant improvement over time, and would not be different from the one-stage colo-anal anastomosis. However, these conclusions are to be taken with caution because of the low level of available evidence. Randomized trials, comparing DCA with one-stage colo-anal anastomosis, will define the place of DCA in rectal surgery [22].

\section{CONFLICT OF INTERESTS:}

Authors declare no conflict of interest.

\section{SOURCE OF FUNDING:}

None

\section{REFERENCES}

1. Cutait DE, Figliolini FJ. A new method of colorectal anastomosis in abdominoperineal resection. Dis Colon Rectum. 1961;4: 335-342.

2. Turnbull RB Jr, Cuthbertson A. Abdominorectal pullthrough resection for cancer and for Hirschsprung's disease. Delayed posterior colorectal anastomosis. Cleve Clin Q. 1961;28: 109-115.

3. Olagne E, Baulieux J, de la Roche E, Adham M, Berthoux N, Bourdeix O, et al. Functional results of delayed coloanal anastomosis after preoperative radiotherapy for lower third rectal cancer. J Am Coll Surg. 2000;191: 643-649.

4. Maggiori L, Blanche J, Harnoy Y, Ferron M, Panis Y. Redo-surgery by transanal colonic pull-through for failed anastomosis associated with chronic pelvic sepsis or rectovaginal fistula. Int J Colorectal Dis. 2015;30: 543-548.

5. Baulieux J, Mabrut JY, Adham M, de La Roche E, Olagne E, Ducerf C, et al. [Excision of low rectal carcinomas with sphincter preservation. Multimodal strategy using neoadjuvant radiotherapy and "delayed" coloanal anastomosis without defunctioning stoma]. Bull Acad Natl Med. 2004;188: 1509-24; 
discussion 1524-7.

6. Kirwan WO, Turnbull RB Jr, Fazio VW, Weakley FL. Pullthrough operation with delayed anastomosis for rectal cancer. Br J Surg. 1978;65: 695-698.

7. Baulieux' J, Olagne' E, Ducerf' C, De La Roche' E, Adham' M, Berthoux' N, et al. Résultats oncologiques et fonctionnels des rections avec anastomose coloanale directe différke dans les cancers du bas rectum préalablement irradiés. Chirurgie. 1999;124: 240-251.

8. Cutait DE, Cutait R, Ioshimoto M, Hyppólito da Silva J, Manzione A. Abdominoperineal endoanal pullthrough resection. A comparative study between immediate and delayed colorectal anastomosis. Dis Colon Rectum. 1985;28: 294-299.

9. Remzi FH, El Gazzaz G, Kiran RP, Kirat HT, Fazio VW. Outcomes following Turnbull-Cutait abdominoperineal pull-through compared with coloanal anastomosis. Br J Surg. 2009;96: 424-429.

10. Kim HJ, Huh JW, Kim HR, Kim YJ. Oncologic impact of anastomotic leakage in rectal cancer surgery according to the use of fibrin glue: case-control study using propensity score matching method. Am J Surg. 2014;207: 840-846.

11. Krarup P-M, Nordholm-Carstensen A, Jorgensen LN, Harling H. Anastomotic leak increases distant recurrence and long-term mortality after curative resection for colonic cancer: a nationwide cohort study. Ann Surg. 2014;259: 930-938.

12. Nesbakken A, Nygaard K, Lunde OC. Outcome and late functional results after anastomotic leakage following mesorectal excision for rectal cancer. $\mathrm{Br} \mathbf{J}$ Surg. 2001;88: 400-404.

13. Portale G, Popesc GO, Parotto M, Cavallin F. Delayed Colo-anal Anastomosis for Rectal Cancer: Pelvic Morbidity, Functional Results and Oncological Outcomes: A Systematic Review. World J Surg. 2019;43: 1360-1369.

14. Hallet J, Milot H, Drolet S, Desrosiers E, Grégoire RC, Bouchard A. The clinical results of the Turnbull-Cutait delayed coloanal anastomosis: a systematic review. Tech Coloproctol. 2014;18: 579-590.

15. Goligher JC, Duthie HL, Dedombal FT, Watts JM. ABDOMINO-ANAL PULL-THROUGH EXCISION FOR TUMORS OF THE MID-THIRD OF THE RECTUM: A COMPARISON WITH LOW ANTERIOR RESECTION. Br J Surg. 1965;52: $323-$ 334.

16. Bianco F, Belli A, De Franciscis S, Falato A, Romano GM. "Scarless" and no-stoma surgery for low rectal cancer: the laparoscopic pull-through delayed "high" colo-anal anastomosis. Updates Surg. 2016;68: 99104.

17. Biondo S, Trenti L, Espín E, Frago R, Vallribera F, Jiménez LM, et al. Complicaciones y mortalidad postoperatorias tras anastomosis coloanal en dos tiempos según técnica de Turnbull-Cutait. Cirugía Española. 2012;90: 248-253.
18. Hallet J, Bouchard A, Drolet S, Milot H, Desrosiers E, Lebrun A, et al. Anastomotic salvage after rectal cancer resection using the Turnbull-Cutait delayed anastomosis. Can J Surg. 2014;57: 405-411.

19. Fixot K, Galifet M, Scherrer M-L, Germain A, Bresler L. Abdominoperineal pull-through resection with delayed coloanal anastomosis as treatment option for complex recto-urinary fistulas. Int $\mathbf{J}$ Colorectal Dis. 2014;29: 407-409.

20. Bozio G, Mabrut J-Y, Baulieux J. Anastomose coloanale «différée », après exérèse totale du mésorectum par laparoscopie, pour cancer du rectum: Delayed colo-anal anastomosis after laparoscopic proctectomy with total mesorectal resectionfor rectal cancer. J Chir . 2008; 145: 262-265.

21. Manceau G, Karoui M, Breton S, Blanchet A-S, Rousseau G, Savier E, et al. Right colon to rectal anastomosis (Deloyers procedure) as a salvage technique for low colorectal or coloanal anastomosis: postoperative and long-term outcomes. Dis Colon Rectum. 2012;55: 363-368.

22. Biondo S, Trenti L, Galvez A, Espin-Basany E, Bianco F, Romano G, et al. Two-stage Turnbull-Cutait pullthrough coloanal anastomosis versus coloanal anastomosis with protective loop ileostomy for low rectal cancer. Protocol for a randomized controlled trial (Turnbull-BCN). Int J Colorectal Dis. 2017;32: 1357-1362.

23. Bianco F, De Franciscis S, Belli A, Ragone V, Romano GM. A pull-through delayed "high" coloanal anastomosis: new tricks to refresh an old procedure. Tech Coloproctol. 2015;19: 259-261.

24. Pujahari AK, Anand S. Trans-anal exteriorisation of colon and delayed colo-anal anastomosis for sphincter preservation in low carcinoma rectum. Int J Colorectal Dis. 2015;30: 853-855.

25. Zanguie M, Abdollahi A, Salek R, Jangjoo A, Jabbari Nooghabi M, Shabahang H, et al. Three Anastomotic Techniques Following Laparoscopic Rectal Cancer Resection: Our Experience in 155 Patients. Surg Innov. 2018;25: 57-61.

26. Prete F, Prete FP. The pull-through: back to the future. G Chir. 2013;34: 293-301.

27. Jarry J, Faucheron JL, Moreno W, Bellera CA, Evrard $\mathrm{S}$. Delayed colo-anal anastomosis is an alternative to prophylactic diverting stoma after total mesorectal excision for middle and low rectal carcinomas. Eur $\mathbf{J}$ Surg Oncol. 2011;37: 127-133.

28. Facy O, Lagoutte N, Jambet S, Radais F, Favre J-P, Rat $\mathrm{P}$, et al. [After low anterior rectal resection, colonic pull-through with delayed colo-anal anastomosis can avoid the need for a diverting ileostomy]. J Chir . 2009;146: 458-463.

29. Barugola G, Bertocchi E, Gentile I, Cracco N, Sartori CA, Ruffo G. Hostile pelvis: how to avoid permanent stoma. Updates Surg. 2018;70: 459-465.

30. Sage P-Y, Trilling B, Waroquet P-A, Voirin D, Girard 


\section{Literature Review}

Journal of Medical and Surgical Research

E, Faucheron J-L. Laparoscopic delayed coloanal anastomosis without diverting ileostomy for low rectal cancer surgery: 85 consecutive patients from a single institution. Tech Coloproctol. 2018;22: 511-518.

31. Xiong Y, Huang P, Ren Q-G. Transanal Pull-Through Procedure with Delayed versus Immediate Coloanal Anastomosis for Anus-Preserving Curative Resection of Lower Rectal Cancer: A Case-Control Study. Am Surg. 2016;82: 533-539. 